\title{
The impact of the intensity of fear on patient's delay regarding health care seeking behavior: a systematic review
}

\author{
Tatiana Dubayova $\cdot$ Jitse P. van Dijk $\cdot$ Iveta Nagyova $\cdot$ \\ Jaroslav Rosenberger • Eva Havlikova - Zuzana Gdovinova • \\ Berrie Middel · Johan W. Groothoff
}

Received: 12 November 2008/Revised: 1 November 2009/ Accepted: 8 January 2010/Published online: 14 May 2010

(C) The Author(s) 2010. This article is published with open access at Springerlink.com

\begin{abstract}
Objectives This systematic review focuses on the role of the intensity of fear in patient's delay in cancer and in myocardial infarction.

Methods In a search of literature published between 1990 and June 2009, 161 articles were found. After the use of inclusion and exclusion criteria, 11 articles in cancer and 4 articles in myocardial infarction remained.

Results High levels of fear are associated with earlier help-seeking in both diseases; for low levels of fear, the picture is unclear.

Conclusion The level of fear is an important factor, which should be taken into account when facilitating helpseeking by patients.
\end{abstract}

Keywords Patient's delay - Help-seeking behavior . Fear · Anxiety

T. Dubayova $(\bowtie) \cdot$ E. Havlikova $\cdot$ Z. Gdovinova

Department of Special Education, Faculty of Pedagogy,

University of Presov, Ul 17. novembra 1,

08001 Presov, Slovakia

e-mail: dubayovat@unipo.sk

J. P. van Dijk · B. Middel · J. W. Groothoff

Department of Social Medicine, University Medical Center

Groningen, University of Groningen, Groningen,

The Netherlands

J. P. van Dijk · I. Nagyova · J. Rosenberger

Department of Educational Psychology and Health Psychology,

Faculty of Arts, Kosice Institute for Society and Health,

University of PJ Safarik, Kosice, Slovakia

T. Dubayova J. P. van Dijk - I. Nagyova - J. Rosenberger .

E. Havlikova · Z. Gdovinova - B. Middel · J. W. Groothoff

Department of Neurology, Faculty of Medicine,

University of PJ Safarik, Kosice, Slovakia

\section{Introduction}

An early visit to the physician is sometimes a matter of life or death. The question is, what is late and what is 'in time' in health care? Early help-seeking has an impact on the success of treatment related to the moment of intervention for a particular disease. For example, the prognosis for breast cancer and melanomas is better for patients if the problem is diagnosed within 3 months (Arndt et al. 2002). Thrombolytic treatment for heart attack is more effective when given within $2 \mathrm{~h}$ (Davalos 2005), though it works best in the first $60 \mathrm{~min}$ (Warnes et al. 2008). To achieve a reduction in mortality from the most prevalent diseases among people of working age [men and women from 15 to 64 years of age (Eurostat 2008)] in European countries [acute myocardial infarction (AMI) and cancer], a better understanding of the reasons for late and delayed diagnosis and consequent treatment in patients with potential symptoms of these diseases is required (Caplan and Helzlsouer 1992; Moser et al. 2007).

Patient's delay is most frequently described as the "length of delay between the onset/discovery/recognition of signs and symptoms and a patient's first visit to a health care/medical provider" (Demissie et al. 2002; Thongsuksai et al. 2000), but more simple descriptions like "time to first presentation of signs or symptoms to a physician" can be found as well (Andersen et al. 1995; Young et al. 2000). In addition, the terms 'help-seeking delay' or 'help-seeking behavior' are frequently used in the literature as a synonym for 'patient's delay'.

In many studies, patient's delay is associated mainly with sociodemographic factors, such as gender, age, socioeconomic status (SES) or marital status, though the findings are equivocal. The strongest evidence exists for longer patient's delay being associated with age and SES 
(without regard to diagnosis). Older people (Arndt et al. 2002; Facione et al. 2002; Montella et al. 2001a; Ottesen et al. 1996) and people from low SES groups (Caplan and Helzlsouer 1992; Dracup and Moser 1997; Facione et al. 2002; Schmidt and Borsch 1990) had a tendency to hesitate in consulting an expert. The relationship between gender and patient's delay is not so strong and varies from 'women had a higher tendency to delay' (in cases of AMI and cases of melanoma) (Betti et al. 2003; Dracup and Moser 1991; Lefler and Bondy 2004; Ottesen et al. 1996; Schmidt and Borsch 1990) to "there is no correlation between patient's delay and gender" (in cases of AMI) (Maynard et al. 1989; Schroeder et al. 1978). The same holds true for education; several studies confirmed the association between a lower level of education and a greater tendency to hesitate in seeking help (Caplan and Helzlsouer 1992; Lefler and Bondy 2004; Montella et al. 2001a, 2001b), but approximately the same number of studies refuted this association (Bleeker et al. 1995; Burgess et al. 1998; Demissie et al. 2002; Yu et al. 2002).

Not only sociodemographic factors influence patient's delay, but clinical variables also appear to be important for making a decision on accessing health care. In many cases, previous medical history has an opposite effect on an early visit to surgery or emergency center. Women with a personal history of benign forms of breast cancer delayed longer in comparison with women without a history of a benign disease (Caplan and Helzlsouer 1992; Dracup et al. 1995). It was also found that patients with typical symptoms of a certain disease seek help sooner. Persons who identified symptoms correctly as originating from the heart received help $1 \mathrm{~h}$ earlier compared to those who attributed their pain to other parts of the body (Dracup and Moser 1991; Lefler and Bondy 2004). Results from breast cancer studies also confirm this association between typical symptoms of the disease and earlier consulting with an expert. Women delayed longer when initial breast symptoms did not include a lump (Burgess et al. 1998) compared to women who detected a breast lump, the latter group waiting significantly less time (Meechan et al. 2003). An important factor for decision-making is knowledge. Patients who came earlier to the emergency room had more knowledge about the cardiovascular system and cardiac symptoms, more appropriate behavior and fewer risk factors when compared with the group of patients who delayed for more than $1.5 \mathrm{~h}$ (Bleeker et al. 1995). This was confirmed by the finding that knowledge is a stimulating factor in the decision-making process about having a disease (Moser et al. 2005; de Nooijer et al. 2001a).

Apart from sociodemographic and clinical variables, psychological factors may also play a role in patient's delay. Several clinical studies mentioned fear as an important psychological factor associated with motivation for treatment or patient's delay (Bish et al. 2005; George et al. 2007; Leeuw et al. 2006). According to the definition, fear is the emotional reaction to a specific, identifiable and immediate threat such as a dangerous animal or an injury, and it has a protective function associated with the fight or flight response (Rachman 1989). Clinically, the terms fear and anxiety are frequently used interchangeably (Leeuw et al. 2006). However, there are differences between these variables from a psychological point of view. Anxiety is a form of negative emotions closely related to fear and is defined as unspecified fear with no clear focus (Hartl and Hartlova 2004). Whereas fear motivates an individual to engage in defensive behaviors, anxiety is associated with preventive behaviors, including avoidance, and may have higher intensity than actual fear. For these reasons, 'being anxious' was defined for the purposes of this paper as having a higher intensity than 'having fear'.

The connection of fear with patient's delay was well described in the Leicester review, where the authors identified two types of fear (fear of embarrassment and fear of cancer) in a review of studies in different types of cancer (Smith et al. 2005). In order to complete the variances of fear, fear of pain may also be included a fact relevant mainly for diseases associated with muscular injuries or delay in the rehabilitation process (George et al. 2007). Feelings, such as worry, fear and anxiety, can be elicited by symptom-induced pain or discomfort, presumed diagnosis and anticipated consequences of treatment, as well as by coping failures and reinterpretations of the illness condition (Cameron et al. 1993). Fear appears to be an important psychological factor in delay, and its intensity may have an influence on early arrival to a health care professional. Studies analyzing the association between patient's delay and fear in patients with cancer and AMI were selected for the review, because these two diseases are the two main causes of death in European countries (Mackenbach et al. 2008). The aim of this paper is to explore the role of the intensity of the perception of fear and anxiety in the help-seeking process in patients with a slow, progressive disease and in those with an acute disease.

\section{Methods}

In June 2009, the electronic databases MEDLINE and PsychINFO were searched for articles meeting the following inclusion criteria: (1) original papers on cancer or AMI, (2) written in English, (3) from the search period 1990 until June 2009 and (4) containing the key words 'patient's delay' or 'help-seeking behavior' or 'treatment- 
seeking behavior' or 'treatment seeking delay' or 'patient acceptance of health care' and 'fear' or 'anxiety'.

Two reviewers (TD and JPvD) independently assessed the studies that were identified during the screening based on information obtained from the title and the abstract of the publications from the first search strategy. When discrepancies appeared, the papers were independently assessed by a third reviewer (JWG). After the first search, both reviewers read the full text of the selected 15 articles.

For this systematic review, we adopted and modified criteria from existing quality assessment lists (van der Mei et al. 2006; den Oudsten et al. 2007). Two reviewers (TD and $\mathrm{JPvD}$ ) assessed the quality of the publications as positive (+), negative (-) or unknown (?) based on the information provided in the article. Disagreements between reviewers were discussed during a consensus meeting. The following four quality criteria were chosen for evaluating the publications:

I. definition and operationalization of patient's delaypatient's delay was defined exactly using a diseasespecific cutoff point which divided the sample into delayers and non-delayers $(+)$, or patient's delay was defined as a continuous variable $(-)$,

II. definition and operationalization of fear or anxietyfear and anxiety were operationalized and defined $(+)$, or they were not clearly defined (-),

III. reliability of measurements of fear or anxiety—using validated measurements for fear and anxiety (e.g. HADS, STAI-T, SCID, LEDS, etc.) (+), qualitative study $(+)$, assessing fear or anxiety only from selfreporting of patients or non-validated scales (-),

IV. sample size-adequate sample size for the statistical method used $(+)$, inadequate sample size for the statistical method used $(-)$

V. statistical analyses-using $t$-tests, chi-square, correlations, regression analyses etc. for $(+)$ or using descriptive statistical methods (means and percentages) (-) for assessment of the relationships between patient's delay and intensity of fear.

For each study, a quality score was calculated. The paper was rated as 'strong evidence' when it had an adequate sample size, used validated measurements and reported statistically significant differences in relation to the patient's delay or fear or used appropriate analytic techniques (qualitative studies). Papers which had an adequate sample size and used a rigorous methodology to ascertain data but used only descriptive statistical methods were rated as having a 'moderate' level of evidence. Papers which used inappropriate methods of collecting relevant data about patient's delay or fear and used insufficient analysis were considered as 'insufficient'.

\section{Results}

Using the first search strategy, 158 articles were found. Additional screening based on authors detected another 16 articles, which were not included in the MEDLINE or the PsychINFO database. Three of the 19 authors consulted also mailed a reference to 3 other articles related to the topic of patient's delay. Thus, the total number of articles found was 177 .

From these 177 articles, 162 were excluded because: they contained irrelevant content; involved studies of children and adolescents; were case reports; were books or book chapters; and because they:

- focused only on the association between patient's delay and progression of disease or the effectiveness of treatment;

- reported on the effectiveness of educational programs for reducing patient's delay;

- concentrated only on the association of patient's delay with sociodemographic factors (e.g. age, gender, educational level, occupation);

- focused only on measuring the time from first signs until first contact with a medical doctor without any further explanation.

The process of applying these criteria is shown in Fig. 1; 15 articles remained for review.

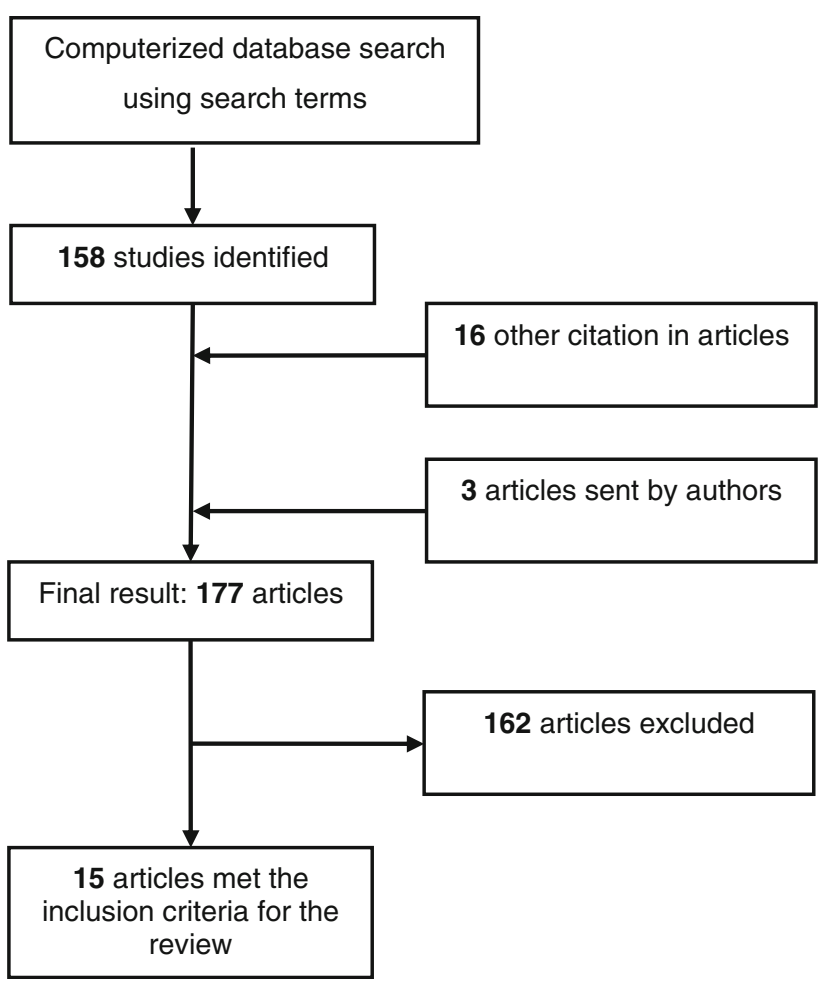

Fig. 1 Flow diagram of the selection process 
Disagreement occurred mainly because of reading errors and differences in the interpretation of the list of criteria, but after the consensus meeting no disagreements persisted. The third reviewer was not asked for a final decision.

\section{Quality assessment}

Only one of the 15 selected studies was rated as 'insufficient'. Eleven were considered as having a 'moderate' level of evidence and three were rated as studies with a 'strong level of evidence' (Table 1).

\section{Study characteristics}

The characteristics of the studies are presented in Table 2. Twelve of the 15 selected studies addressed some form of carcinoma ( 5 on breast cancer, 1 on cutaneous melanomas, 3 on patients with various types of carcinoma, 1 on rectal cancer and 1 on head and neck cancer) and 4 looked at acute myocardial infarction.

In the selected papers, information about patient's delay was obtained from structured or semi-structured interviews with patients or from medical records. The questionnaires contained parts in which the patients were asked about delay and the reasons for delay (Brochez et al. 2001; Burgess et al. 1998; Mor et al. 1990), or the data about delay was obtained from medical records (Dracup and Moser 1997; McKinley et al. 2000; Meechan et al. 2003; Moser et al. 2005). Measuring the concept of fear varied in the selected articles from spontaneous sentences from patients about their fear to standardized measures, where fear was expressed in numbers. Although reliable, validated and standardized measures to assess fear or anxiety are widely used in diagnosis and research [such as the Hospital Anxiety and Depression Scale (HADS), State-Trait Anxiety Inventory-Trait scale (STAI$\mathrm{T}$ ), the Structured Clinical Interview (SCID), the Response to Symptoms Questionnaire and the Bedford College Life Events and Difficulties Schedule (LEDS)], such measures were used in only six of the studies (Burgess et al. 2000; Dracup and Moser 1997; Moser et al. 2005; Ristvedt and Trinkaus 2005; Rozniatowski et al. 2005). In 11 of the 15 analyzed studies, expressions of patients were investigated using a few items from a larger, non-standardized questionnaire or a semi-structured interview. In addition to standardized questionnaires, several authors also used qualitative measures covering many aspects of various domains of the patient's life. They offer a place for spontaneous expressions from the patient's point of view.

How does the intensity of fear influence patient's delay?

Words which described the intensity of fear varied in the reviewed studies from 'being worried' to 'have a fear', 'be

Table 1 The ratings of the 15 studies

\begin{tabular}{|c|c|c|c|c|c|c|c|c|}
\hline \multirow{2}{*}{$\frac{\text { Study, reference }}{\text { Mor et al. (1990) }}$} & \multirow{2}{*}{$\frac{\text { Disease }}{\text { Cancer }}$} & \multirow{2}{*}{$\frac{\text { I }}{+}$} & \multirow{2}{*}{$\frac{\text { II }}{-}$} & \multirow{2}{*}{$\frac{\text { III }}{-}$} & \multirow{2}{*}{$\frac{\text { IV }}{+}$} & \multirow{2}{*}{$\frac{\mathrm{V}}{-}$} & \multicolumn{2}{|c|}{ Evaluation of the study } \\
\hline & & & & & & & $2 / 5$ & M \\
\hline Burgess et al. (1998) & Cancer & + & $?$ & - & + & + & $3 / 5$ & $\mathrm{M}$ \\
\hline Burgess et al. (2000) & Cancer & + & + & + & + & + & $5 / 5$ & $\mathrm{~S}$ \\
\hline Nosarti et al. (2000) & Cancer & + & - & - & + & - & $2 / 5$ & $\mathrm{M}$ \\
\hline Brochez et al. (2001) & Cancer & - & - & - & + & + & $2 / 5$ & $\mathrm{M}$ \\
\hline de Nooijer et al. (2001a) & Cancer & + & + & + & - & - & $3 / 5$ & $\mathrm{M}$ \\
\hline de Nooijer et al. (2001b) & Cancer & + & + & + & - & - & $3 / 5$ & $\mathrm{M}$ \\
\hline Burgess et al. (2001) & Cancer & + & + & - & + & - & $3 / 5$ & $\mathrm{M}$ \\
\hline Meechan et al. (2003) & Cancer & - & + & + & + & + & $4 / 5$ & $\mathrm{~S}$ \\
\hline Rozniatowski et al. (2005) & Cancer & - & + & + & + & + & $4 / 5$ & $\mathrm{~S}$ \\
\hline Rozniatowski et al. (2005) & Cancer & - & + & + & - & + & $3 / 5$ & $\mathrm{M}$ \\
\hline Dracup et al. (1997) & AMI & + & - & - & + & + & $3 / 5$ & $\mathrm{M}$ \\
\hline McKinley et al. (2000) & AMI & - & - & - & + & - & $1 / 5$ & I \\
\hline Kentsch et al. (2002) & AMI & + & - & - & + & - & $2 / 5$ & $\mathrm{M}$ \\
\hline Moser et al. (2005) & AMI & - & - & - & + & + & $2 / 5$ & M \\
\hline
\end{tabular}

$S$ Strong level of evidence, $M$ Moderate level of evidence, $I$ Insufficient level of evidence; Quality criteria: $I$ definition and operationalization of patient's delay_patient's delay was defined exactly using disease specific cut-off point which divided sample on delayers and non-delayers $(+)$, or patient's delay was defined as continuous variable (-); II definition and operationalization of fear or anxiety-fear and anxiety were operationalized and defined (+), or they were not clearly defined (-); III reliability of measurements of fear or anxiety-using validated measurements for fear and anxiety (e.g. HADS, STAI-T, SCID, LEDS etc.) $(+)$, qualitative study $(+)$, assessing fear or anxiety only from selfreporting of a patients or non-validated scales $(-) ; I V$ sample size-adequate sample size to the used statistic method $(+)$, inadequate sample size to the used statistic method (-); $V$ statistical analyses - using $t$ tests, chi-square, correlations, regression analyses etc. for $(+)$ or using descriptive statistic methods (means and percentages) (-) for assessment of the relationships between patient's delay and intensity of fear 


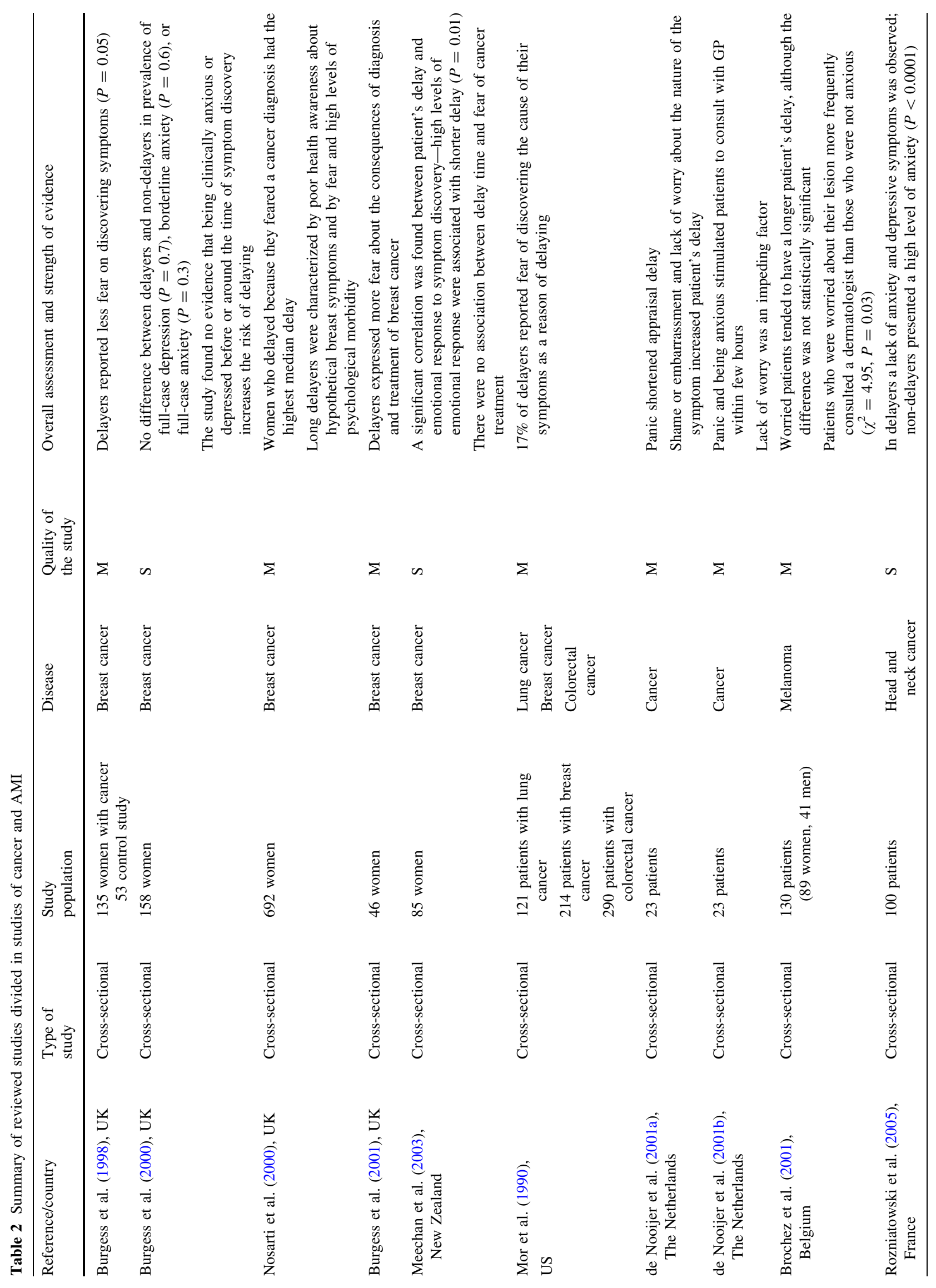


anxious', 'in panic' or 'feel death anxiety'. This sequence reflects the intensity of the emotion of fear.

Cancer

Being only 'worried' by the first signs of disease is not enough stimulus for seeking help in patients with cancer. It appears that patients who were worried tended to have longer patient's delay than those who were not worried, although the difference were not statistically significant $(P=0.07)$ (Brochez et al. 2001). But the same authors also found that patients who were worried about their lesion more frequently consulted a dermatologist than those who were not anxious at all $(P=0.03)$. It can be hypothesized that being worried has no impact on the decision-making process to visit a specialist for the first time, but that it does have an impact on the patient's wish to be treated.

Results of the studies on 'having fear' are contradictory. In patients with different types of carcinoma, $17 \%$ of the delayers reported fear of discovering the cause of their symptoms as the reason for delaying. Delayers with breast cancer mentioned this reason more often than patients with lung or colorectal carcinoma (20.7\% vs. 10.5 and $16 \%$ ) (Mor et al. 1990). It was also found that women who expressed more fear about the consequences of diagnosis and the treatment of the disease delayed longer (Burgess et al. 2001). In a different study, those who delayed were those who reported less fear after discovering the first symptoms of disease $(P=0.05)$; but in contrast, in the same sample more psychological distress (as expressed by the GHQ-12 scores) was associated with longer delay, especially in those who did indeed turn out to have breast cancer (Burgess et al. 1998; Nosarti et al. 2000). In a later analysis, it was found that the influence of fear on decision making is related to various aspects of treatment, the seriousness of the disease, dying or leaving relatives behind (de Nooijer et al. 2001b).

'Being anxious' appears to be a factor which stimulates decision-making in women with breast cancer (Nosarti et al. 2000). This finding was confirmed in a study which shows that there was a lack of anxiety and depression symptoms in patients with large tumor lesions who delayed consultation, whereas patients with smaller lesions with a short delay presented high levels of anxiety $(P=0.00001)$ (Rozniatowski et al. 2005). Using a regression model, not having a breast lump $(\beta=-0.35, t=-3.30, P=0.0001)$ and lower initial symptom distress $(\beta=-0.32, t=-3.03$, $P=0.001$ ) were found to be the factors most predictive of patient's delay (Meechan et al. 2003). However, in other studies, different results were found. It was not confirmed that being clinically anxious or depressed before or around the time of symptom discovery increases the risk of a 
Table 3 Patient's delay and stages of fear

\begin{tabular}{|c|c|c|c|}
\hline & Results & Cancer & AMI \\
\hline Worry & $\begin{array}{l}\text { Worry has no impact on } \\
\text { patient's delay }\end{array}$ & Brochez et al. (2001) & \\
\hline \multirow[t]{2}{*}{ Fear } & $\begin{array}{l}\text { Fear shortened time of patient's } \\
\text { delay }\end{array}$ & $\begin{array}{l}\text { Burgess et al. (1998), Nosarti et al. } \\
\text { (2000) }\end{array}$ & \\
\hline & $\begin{array}{l}\text { Fear prolonged time of } \\
\text { patient's delay }\end{array}$ & $\begin{array}{l}\text { Mor et al. (1990), Burgess et al. } \\
\text { (2001) }\end{array}$ & $\begin{array}{l}\text { Dracup and Moser (1997), } \\
\text { McKinley et al. (2000) }\end{array}$ \\
\hline \multirow[t]{2}{*}{ Anxiety } & $\begin{array}{l}\text { Anxiety shortened time of } \\
\text { patient's delay }\end{array}$ & $\begin{array}{l}\text { Nosarti et al. (2000) Rozniatowski } \\
\text { et al. (2005) Meechan et al. (2003) } \\
\text { Ristvedt and Trinkaus (2005) }\end{array}$ & Moser et al. (2005) \\
\hline & $\begin{array}{l}\text { Anxiety prolonged time of } \\
\text { patient's delay }\end{array}$ & $\begin{array}{l}\text { Burgess et al. (2000) Ristvedt and } \\
\text { Trinkaus (2005) }\end{array}$ & \\
\hline Panic/Death anxiety & $\begin{array}{l}\text { Panic or death anxiety } \\
\text { shortened time of patient's } \\
\text { delay }\end{array}$ & De Nooijer et al. (2001) & Kentsch et al. (2002) \\
\hline
\end{tabular}

woman with symptoms delaying her presentation for medical attention (Burgess et al. 2000). Similar results were reported in a study by Ristvedt and Trinkaus (2005), in which anxiety was measured with a standardized STAI$\mathrm{T}$ questionnaire. Lower scores on STAI-T were associated with fewer doctor visits, so it can be hypothesized that the level of anxiety has a positive correlation with patient's delay (Ristvedt and Trinkaus 2005). However, in the same article, the authors found that people characterized as fearful, shy, tense, and worried had a significantly shorter delay time (Ristvedt and Trinkaus 2005).

Patients who reacted to first symptoms with 'panic' or were 'extremely alarmed' or 'anxious' sought medical help or visited the EMS within a few hours (de Nooijer et al. 2001b). The study showed that panic stimulated patients into inferring illness from the symptoms and shortening appraisal delay as a result.

Acute myocardial infarction

Studies about worries regarding AMI itself were absent, but several studies confirmed that patients with AMI who delayed seeking assistance reported being worried about troubling others with a request for assistance $(P=0.001)$ and feared the financial consequences of seeking help $(P=0.02)$ (Dracup and Moser 1997; McKinley et al. 2000). In patients with AMI 'having fear' is associated with hesitation in seeking help and therefore with longer patient's delay (Burgess et al. 2001). Those patients with AMI who were least anxious about their symptoms delayed seeking medical attention (Moser et al. 2005). Short decision time $(<1 \mathrm{~h})$ was associated in the case of AMI with evaluating symptoms as threatening or dangerous and causing a feeling of 'panic' and 'death anxiety' (Kentsch et al. 2002).
A summary of the findings is presented in Table 3 .

\section{Discussion}

Summary of the main findings

This paper presents the results of 15 studies which investigated patient's delay with the intensity of fear. Levels of intensity of fear were constructed after a detailed reading of the studies. These stages of fear were: 'being worried', 'having fear', 'being anxious', 'being in panic' and 'feeling death anxiety'. Differences in fear between cancer and AMI patients were expected. 'Being worried', 'having fear', and 'being anxious' were mainly present in cancer patients. 'Being worried' is not enough for seeking help with cancer, but it starts the process of internal thinking about the possibility of being treated. The emotion 'fear' seems to be a factor for longer delay, but the decision process in patients experiencing fear was also influenced by other factors, such as embarrassment, pressure from a patient's relatives or fear of financial consequences. 'Being anxious' had a direct impact on shortening patient's delay. These emotions were not present in the case of AMI, but the feeling of 'panic' or 'death anxiety' present in cancer and AMI was associated with seeking help within a few hours of the appearance of the first symptoms of illness; the impact of this type of fear on the patient's delay was similar in both diagnoses.

Meaning of the results

The emotion of fear could lead to either help-seeking behavior or to delay, depending on the cause of the fear and the way people cope with it. The intensity of negative 
feelings seems to be an important predictor of a patient's help-seeking behavior. Of the defined levels of fear ('being worried', 'having fear', 'being anxious', 'in panic' and 'feeling death anxiety'), the latter two have a significantly positive effect on decision-making in help-seeking behavior. Either the first two have no influence on patient's delay (worry) or their impact is ambivalent (fear). Although there are differences in the onset of both diseases, the emotional reaction upon first signs or symptoms were similar. 'Having fear' from treatment, from the consequences of diagnose or from bothering others with bad feelings slowed help-seeking behavior in cancer and in AMI. On the other hand, when patients feel anxiety or panic, according to the results of our review, they seek help sooner in both cases. On this basis, it can be expected that people who are more frightened will have a greater chance of getting medical help earlier than those without such a strong emotional response like in a slow progressive disease-cancer and sometimes also in the case of acute myocardial infarction.

The results of this review also show that minimizing the seriousness of symptoms was negatively correlated with the intensity of fear, making seeking treatment less urgent and producing longer delay. Some authors call this phenomenon health-related 'defensive bias' (Caplan and Helzlsouer 1992), 'optimistic bias' (Andersen et al. 1995) or 'denial' (Moyer and Levine 1999), which leads to longer patient's delay. On the other hand, these behavioral variables were found to be associated with the degree of patient's understanding of the treatment, which is why some authors suggest speaking about 'indecision' rather than about 'denial' (Leslie et al. 2000; Temoshok et al. 1984).

Another explanation for the connection between fear and patient's delay is that people also differ in their perception of symptoms. Some people simply have more symptoms than others, or they differ in the sensation they experience from the same symptom (de Nooijer et al. 2001b). It was observed that some people focus on bodily symptoms more intensely than other people, leading to increased reports of symptoms (Pennebaker 1982). Recognizing pain symptoms has a positive effect on rising anxiety and thus on decision-making in patients with acute myocardial infarction and breast cancer (Caplan and Helzlsouer 1992; Dracup and Moser 1991), but this was not proven in all of the studies (Cameron et al. 1993). The considerable difference between acute pain in cases of acute myocardial infarction and chronic pain in breast cancer occurring in later stages of the disease also has to be taken into account. In the variables of patient's delay between patients with acute myocardial infarction experiencing pain and those without pain, no significant correlations were found (Dracup and Moser 1997). Similar results were found in women with breast cancer (Meechan et al. 2003).
Strengths and limitations

This study is the first which systematically summarizes the influence of the intensity of fear in patient's delay in both a slow, progressive disease and in an acute disease. A limitation of this study was that the analyzed studies did not use the same instruments for measuring fear or anxiety. They varied from standardized instruments like STAI-T, HADS or LEDS to information from semi-structured interviews or self-created questionnaires. Measurement of fear was not the primary aim in several analyzed studies; therefore, the authors did not pay such detailed attention to analyzing the connection of fear or anxiety with patient's delay. Another limitation of the analyses of fear is that, like in all studies examining the relationship between level of fear/anxiety and delay, all patients were assessed retrospectively after they had been admitted to the hospital. The generalizability of the results may be limited by a potential publication bias towards positive findings.

The qualitative evaluation of studies may be also interpreted. Only six of the 15 selected articles use validated measurements of fear or anxiety. In the remaining cases, fear was not the main aim of the study, but it was one of the possible reasons for patient's delay. In six cases, the authors used the patient's delay as continuous variable in the analyses, a fact viewed as a negative factor in this paper. Patient's delay should be interpreted from a diseasespecific point of view, which is why it is preferable to speak about patient's delay only in cases when a patient comes to a health professional after a certain moment which is related to the diagnose. A lack of operationalization of fear or anxiety was observed especially in studies where the author did not used validated measurements. Patients in these studies just reported fear for various reasons, but its intensity or specification is missing. The results of the evaluation of the studies reviewed in this paper should inspire us to be more focused primarily on the association between patient's delay and fear and anxiety.

\section{Conclusion}

There are two ways of coping with fear-fight or flight. The avoidance behavior associated with reduction of fear and anxiety seems to be helpful in the short term because of the reduction of negative feelings, but it may be counterproductive in the long run (Leeuw et al. 2006). Our data explored the possible reasons for patient's delay. The lack of emotional response on symptom discovery can lead to patient's delay in both AMI and cancer. The level of fear evidently influences the decision-making process in patients on help-seeking and hence, this important factor should be taken into account when facilitating help-seeking 
by patients, and especially in cases of low level of fear, encouraging them to seek out medical care. Results of the study suggest that fear might not be disease specific and might have a similar impact on the decision making process in acute as well as slow progressive diagnoses. Unfortunately, the results needed to clarify this point regarding other diseases are missing.

Knowledge about factors associated with patient's delay also could be used in preparing educational programs. Studies suggest that psychological rather than demographic factors are the main predictors of delay time (Nosarti et al. 2000). Therefore, information about clinical variables could be included in the content of such programs, though knowledge about psychological phenomena such as fear and worry can be a more meaningful factor affecting their efficiency. It was observed that health education about cancer mostly tells people how to identify cancer symptoms but provides little about the consequences of a cancer diagnosis (Burgess et al. 2001). Moreover, it was shown that when patients are prepared to anticipate an aversive situation, they are more likely to cope effectively (Dracup and Moser 1997). Further successful cooperation after a patient's first visit to the medical doctor is conditioned by the doctor's communicative skills and his/her proper counseling (Matejic et al. 2008). Health programs for early help-seeking in case of the appearance of the first symptoms of cancer which are oriented only on information about the disease and not on the positive aspects of early diagnosis may increase the fear of a certain diagnosis, which may lead to two types of behavior: denying the initial symptoms or being hypersensitive to any type of small discomforts in the body. Both reactions are strategies with low efficacy for coping with the disease process and may lead to difficulties in help-seeking behavior, a delay which in turn does not contribute to the reduction in mortality aimed for by health policy in most countries.

Acknowledgments This work was supported by the Slovak Research and Development Agency under contract No. APVV-20038305 .

Open Access This article is distributed under the terms of the Creative Commons Attribution Noncommercial License which permits any noncommercial use, distribution, and reproduction in any medium, provided the original author(s) and source are credited.

\section{References}

Andersen BL, Cacioppo J, Roberts DC (1995) Delay in seeking a cancer diagnosis: delay stages and psychophysiological comparison processes. Br J Soc Psychol 34:33-52
Arndt V, Sturmer T, Stegmaier C, Ziegler H, Dhom G, Brenner H (2002) Patient delay and stage of diagnosis among breast cancer patients in Germany: a population based study. Br J Cancer 86:1034-1040

Betti R, Vergani R, Tolomio E, Santambrogio R, Crosti C (2003) Factors of delay in the diagnosis of melanoma. Eur J Dermatol 13:183-188

Bish A, Ramirez A, Burgess C, Hunter M (2005) Understanding why women delay in seeking help for breast cancer symptoms. J Psychosom Res 58:321-326

Bleeker JK, Lamers LM, Leenders IM et al (1995) Psychological and knowledge factors related to delay of help-seeking by patients with acute myocardial infarction. Psychother Psychosom 36:151-158

Brochez L, Verhaeghe E, Bleyen L, Naeyaert JM (2001) Time delays and related factors in the diagnosis of cutaneous melanoma. Eur J Cancer 37:843-848

Burgess CC, Ramirez AJ, Richards MA, Love SB (1998) Who and what influences delayed presentation in breast cancer? $\mathrm{Br} \mathrm{J}$ Cancer 77:1343-1348

Burgess CC, Ramirez AJ, Smith P, Richards MA (2000) Do adverse life events and mood disorders influence delayed presentation of breast cancer? J Psychosom Res 48:171-175

Burgess CC, Hunter MS, Ramirez AJ (2001) A qualitative study of delay among women reporting symptoms of breast cancer. Br J Gen Pract 51:967-971

Cameron L, Leventhal EA, Leventhal H (1993) Symptom representations and affect as determinant of care seeking in a communitydwelling, adult sample population. Health Psychol 12:171-179

Caplan LS, Helzlsouer KJ (1992) Delay in breast cancer: a review of the literature. Public Health Rev 20:187-214

Davalos A (2005) Thrombolysis in acute ischemic stroke: successes, failures and new hopes. Cerebrovasc Dis 20(suppl 2):S135-S139

de Nooijer J, Lechner L, de Vries H (2001a) Help-seeking behavior for cancer symptoms: perceptions of patients and general practitioners. Psychooncology 10:469-478

de Nooijer J, Lechner L, de Vries H (2001b) A qualitative study on detecting cancer symptoms and seeking medical help: an application of Andersen's model of total delay. Patient Educ Couns 42:145-157

Demissie M, Lindtjorn B, Berhane Y (2002) Patient and health service delay in diagnosis of pulmonary tuberculosis in Ethiopia. BMC Public Health 2:23

den Oudsten BL, van Heck GL, de Vries J (2007) Quality of life and related concepts in Parkinson's disease: a systematic review. Mov Disord 11:1528-1537

Dracup K, Moser DK (1991) Treatment seeking behavior among those with signs and symptoms of acute myocardial infarction. Heart Lung 20:570-575

Dracup K, Moser D (1997) Beyond socio-demographic: factors influencing to seek treatment for symptoms of acute myocardial infarction. Heart Lung 26:253-262

Dracup K, Moser DK, Eisenberg M, Meischke H, Alonzo AA, Braslow A (1995) Causes of delay in seeking treatment for heart attack symptoms. Soc Sci Med 40:379-392

Eurostat (2008) The social situation in the European Union 2007. Statistical books 15.06.2009

Facione NC, Miaskowski C, Dodd MJ, Paul SM (2002) The selfreported likelihood of patient delay in breast cancer: new thoughts for early detection. Prev Med 34:397-407

George SZ, Dover GC, Fillingim RB (2007) Fear of pain influences outcomes after exercise-induced delay onset muscle soreness at the shoulder. Clin J Pain 23:76-84

Hartl P, Hartlova H (2004) Psychologicky slovnik. (Lexicon of Psychology). Portal, Praha 
Kentsch M, Rodemerk U, Muller-Esch G et al (2002) Emotional attitudes toward symptoms and inadequate coping strategies are major determinants of patient delay in acute myocardial infarction. Z Kardiol 91:147-155

Leeuw M, Goossens MEJB, Linton SJ, Crombez G, Boersma K, Vlaeyen WS (2006) The fear-avoidance model of musculosceletal pain: current state of scientific evidence. J Behav Med 30:77-94

Lefler LL, Bondy KN (2004) Women's delay in seeking treatment with myocardial infarction-a meta-synthesis. Eur J Cardiovasc Nurs 19:251-268

Leslie WS, Urie A, Hooper J, Morrison CE (2000) Delay in calling for help during myocardial infarction: reasons for the delay and subsequent pattern of accessing care. Heart 84:137-141

Mackenbach JP, Stirbu I, Roskam A-JR, Schaap MM, Menvielle G, Leinsalu M, Kunst AE (2008) Socioeconomic inequalities in health in 22 European countries. N Engl J Med 358:2468-2481

Matejic B, Kesic V, Markovic M, Topic L (2008) Communication about cervical cancer between women and gynecologists in Serbia. Int. J Public Health 53:245-251

Maynard C, Althouse R, Olsufka M, Ritchie JL, Davis KB, Kennedy JW (1989) Early versus late hospital arrival for acute myocardial infarction in the Western Washington thrombolytic therapy trials. Am J Cardiol 63:1296

McKinley S, Moser DK, Dracup K (2000) Treatment-seeking behavior for acute myocardial infarction symptoms in North America and Australia. Heart Lung 29:237-247

Meechan G, Collins J, Petrie KJ (2003) The relationship of symptoms and psychological factors to delay in seeking medical care for breast symptoms. Prev Med 36:374-378

Montella M, Crispo A, Botti G et al (2001a) An assessment of delays in obtaining definitive breast cancer treatment in Southern Italy. Breast Cancer Res Treat 66:209-215

Montella M, Crispo A, D'Aiuto G et al (2001b) Determinant factors for diagnostic delay in operable breast cancer patients. Eur J Cancer Prev 37:843-848 b

Mor V, Masterson-Allen S, Goldberg R, Guadagnoli E, Wool MS (1990) Pre-diagnostic symptom recognition and help seeking among cancer patients. J Community Health 15:253-266

Moser DK, McKinley S, Dracup K, Chung ML (2005) Gender differences in reason patients delay in seeking treatment for acute myocardial infarction symptoms. Patient Educ Couns $56: 45-54$

Moser DK, Kimble LP, Alberts MJ et al (2007) Reducing delay in seeking treatment by patients with acute coronary syndrome and stroke: a scientific statement from the American Heart Association Council on Cardiovascular Nursing and Stroke Council. J Cardiovasc Nurs 22:326-343
Moyer A, Levine EG (1999) Clarification of the conceptualization and measurement of denial in psychosocial oncology research. Ann Behav Med 20:149-160

Nosarti C, Crayford T, Roberts JV, Elias E, McKenzie K, David AS (2000) Delay in presentation of symptomatic referrals to a breast clinic: patient and system factors. Br J Cancer 82:742-748

Ottesen MM, Kober L, Jorgensen S, Torp-Pedersen C (1996) Determinants of delay between symptoms and hospital admission in 5978 patients with acute myocardial infarction. Eur Heart J 17:429-437

Pennebaker JW (1982) The psychology of physical symptoms. Springer, New York

Rachman S (1989) Anxiety. Psychological Press, Hove

Ristvedt SL, Trinkaus KM (2005) Psychological factors related to delay in consultation for cancer symptoms. Psychooncology 14:339-350

Rozniatowski O, Reich M, Mallet Y, Penel N (2005) Psychosocial factors involved in delay consultation by patients with head and neck cancer. Head Neck 4:274-280

Schmidt SB, Borsch MA (1990) The prehospital phase of acute myocardial infarction in the era of thrombolysis. Am J Cardiol 65:1411-1415

Schroeder JS, Lamb IH, Hu M (1978) The prehospital course of patients with chest pain: analysis of the prodromal, symptomatic, decision-making, transportation and emergency room periods. Am J Med 64:742

Smith LK, Pope C, Botha JL (2005) Patient's help-seeking experiences and delay in cancer presentation: a qualitative synthesis. Lancet 366:825-831

Temoshok L, diClemente RJ, Sweet DM, Blois MS, Sagebiel RW (1984) Factors related to patient delay in seeking medical attention for cutaneous malignant melanoma. Cancer 54:30483053

Thongsuksai P, Chongsuvivatwong V, Sriplung H (2000) Delay in breast cancer care: a study of Thai women. Med Care 38:108114

van der Mei SF, Krol B, van Son WJ, de Jong PE, Groothoff JW, van den Heuvel WJ (2006) Social participation and employment status after kidney transplantation: a systematic review. Qual Life Res 15:979-994

Warnes CA, Williams RG, Bashore TM et al (2008) ACC/AHA 2008 guidelines for the management of adults with congenital heart disease. J Am Coll Cardiol 52:e1-e121

Young CJ, Sweeney JL, Hunter A (2000) Implication of delayed diagnosis in colorectal cancer. ANZ J Surg 70:635-638

Yu RF, San Jose MC, Manzanilla BM, Oris MY, Gan R (2002) Sources and reasons for delays in the care of acute stroke patients. J Neurosci 199:49-54 